\title{
PENURUNAN KADAR LOGAM DALAM AIR KADMIUM MENGGUNAKAN ADSORBEN ZEOLIT ALAM ACEH
}

\author{
REMOVAL OF CADMIUM FROM WATER USING NATURAL ZEOLITE ACEH
}

\author{
Cut Raziah ${ }^{1}$, Zerlinda Putri ${ }^{2}$, Atika Rahmi Lubis2, Sofyana2, Zuhra ${ }^{2}$, Suhendrayatna ${ }^{2}$, Sri Mulyati ${ }^{2}$ \\ ${ }^{1}$ Program Studi Magister Teknik Kimia, Program Pascasarjana Universitas Syiah Kuala \\ ${ }^{2}$ Jurusan Teknik Kimia, Fakultas Teknik Universitas Syiah Kuala \\ "email : sri.mulyati@unsyiah.ac.id
}

\begin{abstract}
Abstrak
Limbah logam kadmium (Cd) dalam air tanah merupakan permasalahan yang perlu ditangani dengan serius karena dapat menyebabkan gangguan kesehatan bagi manusia. Berbagai metode pemisahan logam Cd dalam air tanah telah dilakukan diantaranya metode adsorpsi, oksidasi, filtrasi, membran dan lain-lain. Pada penelitian ini digunakan proses adsorbsi menggunakan zeolit alam Aceh. Proses ini diharapkan dapat mereduksi logam $\mathrm{Cd}$ seefektif mungkin. Proses adsorpsi dilakukan dengan variasi waktu kontak, dosis adsorben, $\mathrm{pH}$, dan konsentrasi awal logam Cd. Hasil analisa kristalisasi nano zeolit alam Aceh menggunakan X-Ray Fluorescence (XRF) dengan perbandingan Si/Al zeolit 4,36\%. Analisis kualitas air terhadap kandungan logam $\mathrm{Cd}$ menggunakan alat atomic adsorption Spectrophotometer (AAS) standar AA 630. Hasil penelitian menunjukkan bahwa isotermal adsorbsi dari zeolit alam terhadap logam kadmium mengikuti isotherm freundlich. Sedangkan kinetika adsorpsi dari proses adsorbsi logam kadmium dengan menggunakan zeolit adalah orde dua semu dengan $\mathrm{k}_{2}$ adalah 1,53 .
\end{abstract}

Kata kunci: nano-zeolite, logam Cd, kinetika adsorpsi, isotermal.

\begin{abstract}
The presence of Cadmium $(C d)$ in groundwater is an issue that needs serious handling as it causes problems to human health. The removal of Cadmium $(\mathrm{Cd})$ can be done by various methods such as adsorption, oxidation, filtration, and many more. In this study, the method used was adsorption using Aceh natural zeolite. This process was expected to reduce Cd metal as effectively as possible. The adsorption was conducted by varying contact time, adsorbent dosage, $p H$ and initial concentration of Cd metal. The crystallized Aceh natural zeolite was characterized by X-Ray Fluorescence (XRF) with Si/Al zeolite ratio of $4.36 \%$. The concentration of Cadmium in water was analyzed by means of Atomic Adsorption Spectrophotometer (AAS) standard AA 630. The results showed that the adsorption of cadmium in water solution by Aceh natural zeolite occurred according to the Freundlich adsorption model. While the adsorption kinetic from the process was found to be a pseudo second order with $k_{2}$ value of 1.53 .
\end{abstract}

Keywords: nano-zeolite, Cd metal ion, the adsorption kinetic, isotherm.

\section{Pendahuluan}

Air merupakan kebutuhan pokok yang sangat penting untuk berbagai keperluan dalam setiap kehidupan mahluk hidup. Secara umum pemakaian air digunakan dalam tiga sektor yaitu sektor pertanian $(70 \%)$, sektor industri $(19 \%)$ dan sektor domestik (11\%) [2]. Pada saat ini polutan-polutan berbahaya telah mencemari sebagian besar air tanahyang dapat menimbulkan masalah bagi kesehatan manusia. Salah satu polutan tersebut adalah adanya logam berat yang terdapat pada air. Keberadaan logam menjadi perhatian penting karena senyawa ini bersifat toksis, non biodegradable dan mempunyai tendensi yang terakumulasi dalam organisme hidup $[12,14,16]$. Logam berat masuk ke lingkungan berasal dari aktivitas industri seperti industri pengolahan logam, pembuatan baterai, penyamakan, metalurgi dan industri pembuatan pupuk. Logam berat masuk ke dalam tubuh melalui pernafasan, tertelan melalui makanan dan juga teradsorpsi melalui kulit [6].

Logam berat berbahaya yang dapat mencemari lingkungan terdiri dari kadmium (Cd), krom (Cr), nikel (Ni), merkuri (Hg), timbal $(\mathrm{Pb})$, dan arsen (As). Setelah Merkuri (Hg), 
logam kadmium (Cd) merupakan unsur logam berat yang paling beracun. Oleh sebab itu perlu dilakukan penanganan khusus dalam menentukan metode yangefisien dan efektif untuk menghilangkannya didalam air tanah. Pemerintah menetapkankadar maksimum $\mathrm{Cd}$ dalam air minum yaitu $0,01 \mathrm{mg} / \mathrm{l}$ yang tetuang didalam Peraturan Menteri Kesehatan RI No.492/Menkes/Per/IV/2010.

Berbagai macam teknologi yang telah dilakukan untuk dapat mengurangi kandungan logam Cd didalam air seperti adsorpsi $[1,5,6,7,9]$. Sejauh ini proses adsorpsi menjadi proses yang paling banyak digunakan karena proses ini mudah, sederhana dan ramah terhadap lingkungan [16]. Adsorben yang umum digunakan antara lain zeolit, tanah lempung, karbon aktif, biomassa dan material polimer. Adsorben tersebut memiliki kapasitas adsorbsi yang rendah.

Seiring dengan adanya perkembangan nanoteknologi yang semakin pesat telah banyak dilakukan penelitian tentang partikel-partikel berukuran nanometer. Untuk ion logam zeolit dengan ukuran nano partikel dimanfaatkan sebagai media pertukaran ion, selain itu juga sebagai adsorben yang sangat efektif dalam penyerapan ion logam. Secara parsial pemisahan dengan metode adsorpsi dan filtrasi telah dilakukan oleh sejumlah peneliti, akan tetapi belum memberi hasil secara optimal. Hybrid nano zeolit adsorpsi merupakan salah satu pilihan proses yang dapat digunakan untuk menghilangkan logam $\mathrm{Cd}$ yang terkandung di dalam air tanah. Proses ini diharapkan dapat memberi efisiensi proses yang lebih baik. Penggunaan nano-partikel sebagai media penyerap diharapkan dapat memberikan kapasitas adsorpsi yang lebih baik.

Proses adsorpsi logam Cd dilakukan dengan menggunakan zeolit alam Ujung Pancu Aceh sebagai adsorben. Zeolit alam dikecilkan sampai ukuran nano. Kemudian larutan sampel dimasukkan ke dalam kolom adsorpsi yang berisi nano-zeolitalam Aceh sehingga terjadi proses penyerapan logam $\mathrm{Cd}$. Variabel waktu kontak, pH sampel, dosis adsorben dan konsentrasi awal sampel diuji untuk diketahui efisiensi penyisihan logam Kadmium. Selanjutnya dipelajari isothermal adsorpsi dan kinetika reaksi.

Kualitas larutan sampel hasil penyisihan logam Cd dengan cara adsorpsi diukur dengan menggunakan sebuah alat Atomic Adsorption Spectrophotometer (AAS) shimadzu AA 630,

Metode penelitian

Penyiapan Adsorben Nano Zeolit Alam
Adsorben yang digunakan adalah zeolite alam Aceh. Zeolit alam yang berbentuk bebatuan dibersihkan dari bahan pengotor. Batu zeolit alam ditumbuk dengan palu stainless stelluntuk memperkecil ukuran hingga dapat dijadikan umpan alat penghalus (ball-mill). Setelah halus zeolit disaring dengan menggunakan ukuran ayakan 200 mesh, hasil yang lolos dari ayakan dihaluskan kembali dengan menggunakan ball mill selama 10 jam sampai didapat ukuran nanopartilkel.

\section{Karakterisasi Adsorben nano zeolite alam Aceh \\ Uji komposisi kimia adsorben nano zeolite dilakukan dengan menggunakan alat $\mathrm{X}$ - Ray Fluorescene (XRF). Sampel disinari dengan sinar-X yang menyebabkan terjadinya emisi fluoresens sinar-X. \\ Pengaruh waktu kontak terhadap penyerapan logam Cd}

Adsorben sebanyak $10 \mathrm{~g}$ dimasukkan kedalam beaker glass $250 \mathrm{~mL}$, kemudian sampel logam dengan konsentrasi tertentu ditambahkan sebanyak $100 \mathrm{~mL}$. Kemudian dilakukan pengadukan selama 120 menit. Setiap interval 20 menit sampel diambil dan dianalisa kandungan logam kadmium yang terdapat di dalam sampel. Variabel konsentrasi logam Cd dalam sampel (20,40,60,80, dan 100) mg/l. Kecepatan putaran pengaduk adalah $100 \mathrm{rpm}$. Setelah itu filtrat disaring dan dilakukan analisa logam kadmium yang terkandung dalam filtrat.

\section{Pengaruh dosis adsorben terhadap penyerapan logam $\mathrm{Cd}$}

Dosis adsoben yang divariasikan terdiri dari $(1,2,3,4,5,6,7,8,9$, dan 10) g. Percobaan dilakukan dengan mengontakkan sampel logam dengan konsentrasi tetap yaitu $40 \mathrm{mg} / \mathrm{l}$. Proses adsorbsi dilakukan selama 40 menit dengan kecepatan putaran pengaduk $100 \mathrm{rpm}$.

\section{Pengaruh pH sampel terhadap penyerapan logam Cd}

pH sampel divariasikan 3, 4, 5, 6, 7, 8, dan 9, kemudian masing-masing sampel dengan variasi pH dikontakkan dengan adsorben. Dosis adsorben yang digunakan $10 \mathrm{~g}$, konsentrasi sampel $40 \mathrm{~g} / \mathrm{mL}$ dan volume sampel sebanyak $250 \mathrm{~mL}$.

\section{Hasil \\ Karakteristik nanozeolite alam Aceh}

Hasil karakterisasi nanozeolite alam Banda Aceh ditunjukkan pada Tabel 1. Dari hasil analisa tersebut terlihat bahwa kandungan silika dan 
alumina mendominasi komposisi kimia dari zeolite alam Aceh.

Perbandingan rasio $\mathrm{Si} / \mathrm{Al}$ yang dimiliki oleh zeolit alam tanpa aktivasi sebesar 4,363, yang menunjukkan kerapatan atom $\mathrm{Si}$ pada struktur kerangka kristal zeolit cukup tinggi. Zeolit dengan kandungan silika tinggi memiliki sifat hidrofobik, sebaliknya untuk zeolit dengan kandungan alumina tinggi bersifat hidrofilik [20].

Tabel 1. Karakterisasi Zeolit Alam Dengan XRF Tanpa Aktivasi

\begin{tabular}{|c|c|}
\hline Senyawa & $\begin{array}{c}\text { Komposisi (\%) } \\
\text { Berat) }\end{array}$ \\
\hline $\mathrm{SiO}_{2}$ & 53,56 \\
\hline $\mathrm{Al}_{2} \mathrm{O}_{3}$ & 20,83 \\
\hline $\mathrm{Fe}_{2} \mathrm{O}_{3}$ & 11,46 \\
\hline $\mathrm{CaO}$ & 5,7 \\
\hline $\mathrm{MgO}$ & 3,58 \\
\hline $\mathrm{SO}_{3}$ & 0,05 \\
\hline $\mathrm{K}_{2} \mathrm{O}$ & 1,35 \\
\hline $\mathrm{Na}_{2} \mathrm{O}$ & 1,27 \\
\hline $\mathrm{P}_{2} \mathrm{O}_{5}$ & 0,172 \\
\hline $\mathrm{TiO}_{2}$ & 1,098 \\
\hline $\mathrm{Mn}_{2} \mathrm{O}_{3}$ & 0,164 \\
\hline $\mathrm{Cr}_{2} \mathrm{O}_{3}$ & 0,009 \\
\hline Loss $\mathrm{On} \mathrm{Ignition}_{2}$ & 7,98 \\
\hline
\end{tabular}

\section{Pengaruh Waktu Kontak}

Pengaruh waktu kontak terhadap adsorpsi logam kadmium oleh adsorben zeolit dilakukan dengan cara mencampurkan $100 \mathrm{ml}$ sampel logam kadmium dengan konsentrasi $40 \mathrm{mg} / \mathrm{L}$ pada $10 \mathrm{~g}$ adsorben ke dalam beaker glass. Kemudian dilakukan pengadukan dengan kecepatan 100 rpm.

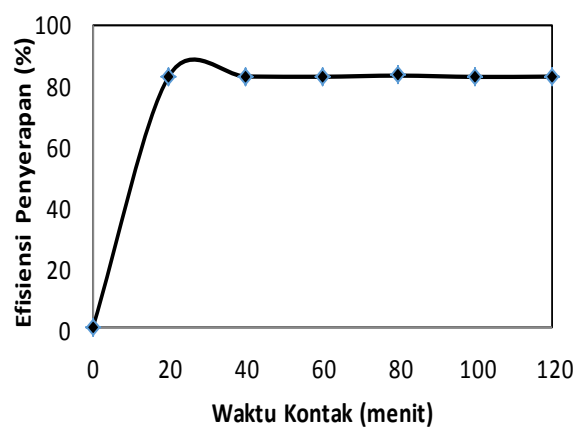

Gambar 1. Pengaruh waktu kontak terhadap efisiensi penyerapanlogam Kadmium
Gambar 1 menunjukkan pengaruh waktu kontak terhadap penyisihan logam kadmium. Dari gambar diatas dilihat pengaruh waktu kontak terhadap efisiensi penyisihan logam kadmium berkisar antara 0-20 menit pertama efiensi kenaikan cukup signifikan, hal ini dikarenakan ketersediaan permukaan kontak yang masih cukup banyak untuk menyerap logam kadmium. Kenaikan interval waktu selanjutnya tidak memberikan kenaikan yang cukup berarti,dikarenakan difusi yang lambat dari kation ke dalam pori zeolit [19]. Adsorpsi optimum terjadi pada waktu kontak 40 menit dengan effisiensi penyerapan sebesar $83,041 \%$.

\section{Pengaruh Dosis Adsorben}

Dosis adsorben juga merupakan variabel yang berpengaruh pada proses adsorpsi, karena dapat menentukan kapasitas adosrbsi sebuah adsorben pada konsentrasi awal dari adsorbat [13]. Disamping itu dosis adsorben juga dapat menentukan kuantitas logam yang teradsorpsi. Semakin banyak zeolit yang ditambahkan per satuan volume air tanah akan meningkatkan massa logam berat terlarut yang teradsorpsi [17]. Pengaruh dosis adsorben terhadap efisensi penyerapan dapat dilihat pada Gambar 2. Dari gambar terlihat efisiensi penyerapan meningkat secara signifikan dengan kenaikan dosis adsorben dari $0-10 \mathrm{~g} / \mathrm{l}$. Kenaikan dosis selanjutnya tidak memberikan peningkatan kemampuan penyerapan. Hal ini dikarenakan dosis adsorben yang besar menyebabkan terjadinya agregat dari partikel sehingga menurunkan luas permukaan spesifik menyebabkan efisiensi penyerapan rendah [4]. Dengan demikian massa adsorben tanpa aktivasi sebesar $1 \mathrm{~g}$ dianggap lebih baik penyerapanannya, dengan persen removal sebesar $81,813 \%$.

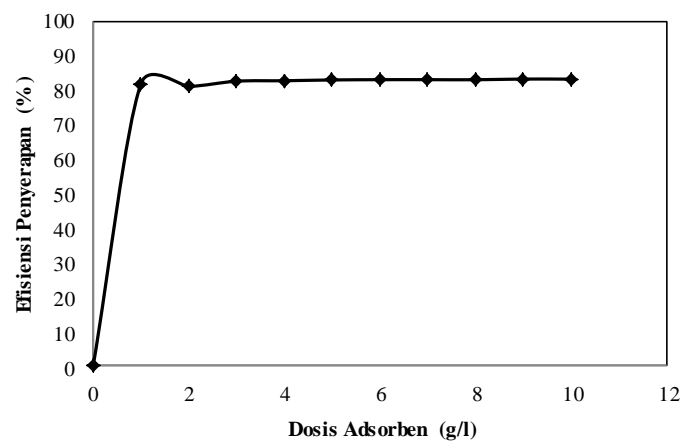

Gambar 2. Pengaruh dosis adsorben denganefisiensi penyerapan pada logam kadmium 


\section{Pengaruh pH}

Kondisi pH awal dari larutan logam merupakan salah satu variabel yang sangat penting pada proses adsorpsi. Kapasitas serapan dari ion logam dan mekanisme adsorpsi dipengaruhi oleh kondisi $\mathrm{pH}$ larutan [3]. $\mathrm{pH}$ larutan juga dapat mempengaruhi muatan pada permukaan adsorben. Nilai $\mathrm{pH}$ juga dapat mempengaruhi kesetimbangan kimia, baik pada adsorbat maupun pada adsorben. Pada penelitian ini $\mathrm{pH}$ divariasikan menjadi $(3,4,5,6,7,8$, dan 9) dengan konsentrasi $\mathrm{Cd}$ sebesar $43,8 \mathrm{mg} / \mathrm{l}$ pada waktu 40 menit. Pengaruh $\mathrm{pH}$ terhadap efisiensi penyerapan dapat dilihat pada Gambar 3.

Dari gambar terlihat bahwa pada kondisi $\mathrm{pH}$ asam efisensi penyerapan logam kadmium rendah. Hal ini dikarenakan pada kondisi ini permukaan dari sisi aktif dari adsorben bermuatan positif sehingga terjadi kompetisi antara ion hydronium dan ion logam [6]. Efisiensi penyerapan meningkat pada $\mathrm{pH} 6$ dan mencapai nilai maksimum yaitu $81,856 \%$ tanpa aktivasi. Peningkatan $\mathrm{pH}$ sampai $\mathrm{pH}$ 6, permukaan aktif dari adsorben menjadi negatif menyebabkan ion kadmium akan lebih mudah teradsorpsi karena adanya gaya elektrostatik antara permukaan adsorben dan logam kadmium. Pada range pH 7 - 9, efisiensi penyerapan logam menurun, hal ini diakibatkan terjadinya pengendapan dari ion kadmium sebagai senyawa hidroksid $\left(\mathrm{Cd}(\mathrm{OH})_{2}\right)$ [4].

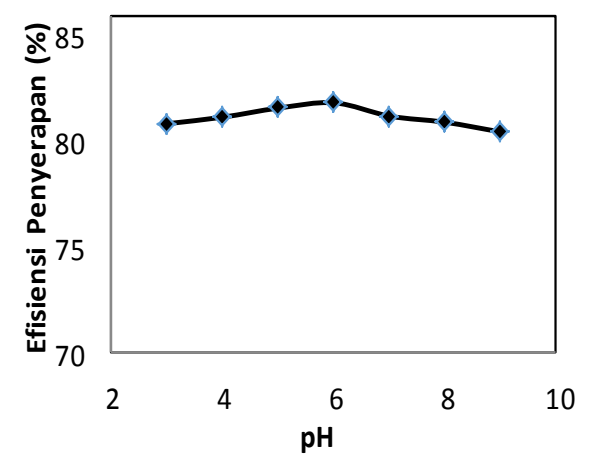

Gambar 3 Pengaruh pH sampel terhadap efisensi penyerapan logam kadmium pada konsentrasi $43,8 \mathrm{mg} / \mathrm{l}$

\section{Isoterm Adsorpsi}

Terdapat dua jenis isotermal yang umum yang ditinjau pada penelitian ini yaitu isotermal Langmuir dan Freundlich. Isoterm Langmuir mengambarkan ikatanyang terjadi pada proses adsorpsi adalah ikatan kimia, sedangkan pada isotherm freundlich mengambarkan ikatan yang terjadi adalah ikatan fisika [10]. Pada Gambar 4 menunjukkan grafik hasil perhitungan secara
Langmuir dan freundlich. Dari grafik didapat nilai koefisien determinasi $\left(\mathrm{R}^{2}\right)$ dari persamaan isotherm Freundlich sebesar 0,98, sedangkan isotherm Langmuir adalah 0,67. Ini menunjukkan ikatan yang terjadi pada proses adsorpsi $\mathrm{Cd}$ oleh nano zeolit tanpa aktivasi didominasi oleh ikatan fisika karena nilai determinasi $\left(\mathrm{R}^{2}\right)$ isotherm freundlich lebih besar dengan nilai $\mathrm{K}_{\mathrm{f}}$ adalah 0,082 .

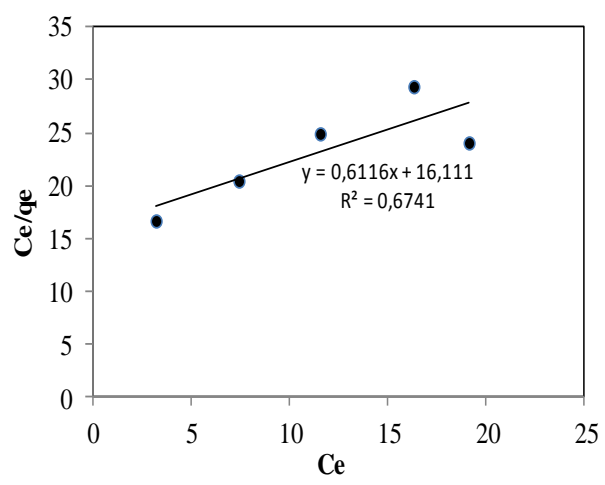

(a)

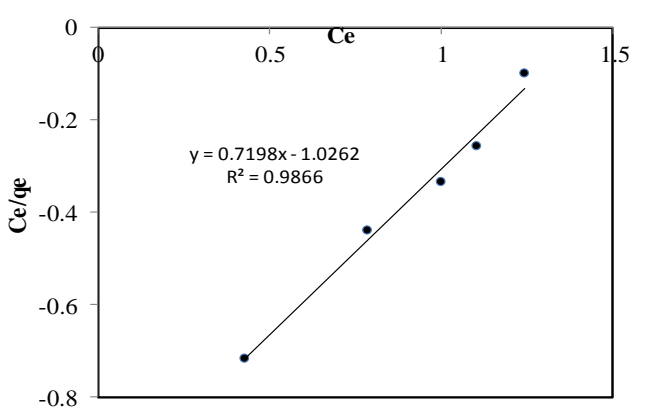

(b)

Gambar 4. Isotermal adsorbsi nanozeolit alam Aceh, a : isotermal Langmuir; b : isotermal Freunlich

\section{Kinetika Adsorpsi}

Parameter kinetika reaksi untuk adsorbsi logam Cd menggunakan zeolit alam Aceh ditabulasikan pada Tabel 2 .

\begin{tabular}{|l|c|c|c|}
\hline $\begin{array}{l}\text { Parameter } \\
\text { kinetika } \\
\text { reaksi }\end{array}$ & $\boldsymbol{q} \boldsymbol{\boldsymbol { K } _ { \boldsymbol { I } }}$ & $\boldsymbol{R}^{2}$ \\
\hline $\begin{array}{l}\text { Orde satu } \\
\text { semu }\end{array}$ & 0,0119 & $9,6726 \times 10^{-2}$ & 0,616 \\
\hline $\begin{array}{l}\text { Orde satu } \\
\text { semu }\end{array}$ & 0,5379 & 1,5312 & 0,997 \\
\hline
\end{tabular}

Dari Tabel 1 memberi penjelasan tentang tingkat akurasi sebaran data hubungan antara waktu kontak dengan kapasitas adsorpsi. Harga koefisien determinasi pada kinetika order satu 
semu yaitu 0,616 dan kinetika order dua semu adalah 0,997. Sebaran data order satu semu memiliki akurasi lebih kecil dibandingkan harga order dua semu. Fenomena adsorpsi logam kadmium oleh zeolit alam Banda Aceh terjadi menurut order dua semu.

\section{Kesimpulan}

Nano zeolite alam berpotensi digunakan sebagai adsorben untuk menyerap logam $\mathrm{Cd}$. Waktu kontak, dosis adsorben, $\mathrm{pH}$ sampel logam mempengaruhi efisiensi penyerapan logam $\mathrm{Cd}$ oleh nanozeolite alam Aceh. Waktu kontak optimum adalah 40 menit, dosis adsorben sebanyak $2 \mathrm{~g}$ dalam $250 \mathrm{ml}$ sampel, $\mathrm{pH}$ sampel adalah netral. Isotermal dan kinetika adsorbsi dari nano zeolit alam pada penyerapan logam $\mathrm{Cd}$ dalam larutan sampel mengikuti isotermal Freunlich dan orde dua semu.

\section{Ucapan Terima Kasih}

Penulis mengucapkan terimakasih kepada Direktorat Penelitian dan Pengabdian kepada Masyarakat Kementrian Riset, Teknologi dan Pendidikan Tinggi melalui Hibah penelitian Fundamental

\section{Daftar Pustaka}

[1] A. A. Baba., F. A. Adekola, Solvent extraction of $\mathrm{Pb}(\mathrm{II})$ and $\mathrm{Zn}(\mathrm{II})$ from a Nigerian galena ore leach liquor by tributylphosphate and bis(2,4,4trimethylpentyl)phosphinic acid, Journal of King Saud University - Science ,25, (2013) 297-305

[2] Alimohammadi, N.,Shadizadeh, S. R., Kazeminezhad, I, (2013), Removal of cadmium from drilling fluid using nanoadsorbent, Fuel,111, (2013)505-509.

[3] A.Heidari, Younesi, Mehraban, Heikkinen, Selective Adsorption Of $\mathrm{Pb}(\mathrm{II}), \mathrm{Cd}(\mathrm{II})$, And $\mathrm{Ni}(\mathrm{II})$ Ions From Aqueous Solution Using Chitosan-MAANanoparticles, International Journal of Biological Macromolecules., 61 (2013) 251-263.

[4] A. Sari, and M. Tuzen, Cd(II) Adsorption From Aqueous Solution By Raw And Modified Kaolinite, Applied Clay Science, 88-89 (2014) 63-72.

[5] Coelho, G. F., Gonçalves Jr, A. C., Tarley, C. R. T., Casarin, J., Nacke, H., Francziskowski, M. A, Removal of metal ions $\mathrm{Cd}$ (II), $\mathrm{Pb}$ (II), and $\mathrm{Cr}$ (III) from water by the cashew nut shell Anacardium occidentale L, Ecological Engineering, 73, (2014) 514-525.
[6] D. Ozdes, C. Duran,H. B. Senturk, Adsorptive removal of $\mathrm{Cd}$ (II) and $\mathrm{Pb}$ (II) ions from aqueous solutions by using Turkish illitic clay, Journal of Environmental Management,92, (2011). 3082-3090.

[7] E. Carasek, J. Wick Tonjes, M. Scharf, A new method of microvolume backextraction procedure for enrichment of $\mathrm{Pb}$ and $\mathrm{Cd}$ and determination by flame atomic absorption spectrometry, Talanta,56, (2002) 185-191.

[8] F. M. Pang, P. Kumar, T. T.Teng, A. K., Mohd Omar, K. L. Wasewar, Removal of lead, zinc and iron by coagulationflocculation." Journal of the Taiwan Institute of Chemical Engineers, 42, (2011), 809-815.

[9] G.R. Jamshidi, W.J. Lau, T. Matsuura, E. Halakoo, A. F. Ismail, Adsorptive removal of $\mathrm{Pb}(\mathrm{II})$ from aqueous solution by novel PES/HMO ultrafiltration mixed matrix membrane,Separation and Purification Technology, 120 (2013) 59-68.

[10] H. Murni. S. Eko S, Prosiding Seminar Nasional Sains dan Teknologi Nuklir, Batan Bandung, 2009.

[11] I. Syauqiah, A.K. Mayang, Analisis Variasi Waktu Dan Kecepatan Pengaduk Pada Proses Adsorpsi Limbah Logam Berat Dengan Arang Aktif, Info Teknik, Staf Pengajar Fakultas Teknik Unlam Banjarmasin.12, (2011),No.1.

[12] J. Anwar, U. Shafique, Z. Waheed, M. Salman, A. Dar, A. Shafique, Removal of $\mathrm{Pb}$ (II) and $\mathrm{Cd}$ (II) from water by adsorption on peels of banana,Bioresource Technology 101, (2010) 1752-1755.

[13] L. Zheng, Dang, X. Zhu, Yi, Zhang and Liu, Removal Of Kadmium(II) From Aqueous Solution By Corn Stalk Graft Copolymers." Bioresource Technology, 101 (2010) 58205826.

[14] M.q. Jiang, X.y. Jin, X.Q.Lu, Z.1., Chen, Adsorption of $\mathrm{Pb}(\mathrm{II}), \mathrm{Cd}(\mathrm{II}), \mathrm{Ni}(\mathrm{II})$ and $\mathrm{Cu}(\mathrm{II})$ onto natural kaolinite clay.252, Desalination, 252,(2010), 33-39.

[15] Peraturan Pemerintah No. 82 Tahun 2001 tangal 14 Desember 2001, Tentang Pengelolaan Kualitas Air Baku Dan Pengendalian Pencemaran Air, Jakarta.

[16] Q. Tang, X. Tang, M. Hu, Z. Li, Y.Chen, P. Lau, Removal Of Cd(II) From Aqueous Solution With Activated Firmiana Simplex Leaf: Behaviors And Affecting Factors, Journal of Hazardous Materials, 179 (2010) 95-103. 
[17] Suprihatin, (2010), "Penyisihan Logam Berat Dari Limbah Cair Laboratorium Dengan Metode Presipitasi Dan Adsorpsi”, Departemen Teknologi Industri Pertanian, Fakultas Teknologi Pertanian, Institut Pertanian Bogor, Makara, Sains, 14 (2010).No. 1.

[18] T. K. Naiya, A. K. Bhattacharya, Das, S. $\mathrm{K}$., Adsorption of $\mathrm{Cd}(\mathrm{II})$ and $\mathrm{Pb}$ (II) from aqueous solutions on activated alumina, Journal of Colloid and Interface Science, 333, (2009)14-26.

[19] T. Motsi, Rowson and Simmons, "Kinetic Studies Of The Removal Of Heavy Metals From Acid Mine Drainage By Natural Zeolit, International Journal of Mineral Processing, 101, (2011) 42-49.

[20] Y.C. Sharma, dan V. Srivastava, Adsorption Of Cadmium (II) From Aqueous Solution By An Indigenous Clay Mineral, Indian Journal Of Chemical Technology, 13 (2006) 218-221.

[21] Z. Abdeen, S. G. Mohammad, M. S. Mahmoud, Adsorption of Mn (II) ion on polyvinylalcohol / chitosan dry blending from aqueous solution, Environmental Nanotechnology, Monitoring \& Management, 3, (2015) 1-9. 